DOI:

\title{
The Effect of Relaxation techniques on Quality of Sleep for Patients with End Stage Renal Failure Undergoing Hemodialysis
}

\author{
Safaa Eid Sayed ${ }^{1}$ and Gehan Abd Alhkeem Younis ${ }^{2}$ \\ ${ }^{12}$ Lecturer of Critical-Care Nursing
}

\begin{abstract}
Many patients on regular hemodialysis have sleep disorders, which not only affect their quality of life but also their immune function. Relaxation techniques are simply designed to teach the patients to relax, and thus improve their ability to sleep. The purpose of the study was to evaluate the effect of relaxation techniques on the quality of sleep of patients with end stage renal failure undergoing hemodialysis. The study was carried out in hemodialysis unit at Mobark Hospital, Tanta University Hospital. A convenient sample of 20 adult patients undergoing hemodialysis was selected, with one group, before and after intervention. Two instruments were used for data collection. Instrument one includes Scio demographic data assessment. Instrument two includes Pittsburgh Sleep Quality Index Scale that measures the sleep quality. The main result showed that relaxation technique improved the total score of sleep quality and its dimensions in hemodialysis patients. It is recommended that Periodic clinical assessment of sleep complaints should become routine for dialysis patients. Also, no pharmacological methods such as relaxation techniques should be used for the treatment of sleep problems in hemodialysis patients.

Key words: Relaxation techniques, End stage Renal Failure, Quality of Sleep, Hemo dialysis
\end{abstract}

\section{Introduction:}

Chronic Kidney Disease is a worldwide public health problem and is defined as kidney damage for 3 or more months with or without decreased in GFR. Endstage renal disease (ESRD) is one of the main health problems in Egypt and the estimated annual incidence is around 74 per million and the total prevalence of patients on dialysis is 264 per million(Shu and Te-Cheng, 2011; Lashkari, Shariati, Baraz and Latifi, 2013; Merlino et al., ,2006; and Ahmed et al., 2010)

Sleep has been identified as an essential human need because of the metabolic activities that occur during sleep. A good sleep is very important to the quality of life for everyone ((Shu and Te-Cheng, 2011; Mollaoğ, 2011).

With advances in dialysis techniques and medical care, mortality and morbidity rates of patients on regular hemodialysis have markedly decreased, and further improvement of dialysis clearance is no longer the sole goal for these patients. On the other hand, improvement in life quality of patients has become the new aim of medical practitioners today as many patients on dialysis suffer from sleep disorders (Mollaoğ, 2011).

According to previous studies, around $50-80 \%$ of dialysis patients have problems associated with sleep disorders, including difficulty in falling asleep, waking up early, daytime sleepiness, leg jerking and trembling. Also, Poor sleep quality affects many hemodialysis patients and can leave a significant negative impact on their quality of life and health status (Shu and Te-Cheng, 2011).

It is also associated with development of cardiovascular disease, physical, behavioral and psychological problems such as mental and social dysfunction. Increased stress, anxiety, depression and worry are also associated with poor 


\section{The Effect of Relaxation techniques on Quality of Sleep for Patients with End Stage Renal Failure Undergoing Hemodialysis}

sleep quality in dialysis patients. All these sleep disorders lead to a reduction of quality of life (Shu and Te-Cheng, 2011, Harris et al.,2012 and Santo et al., 2006).

There are different methods used to treat sleep disorders including; the use of sleep medications, which are effective in short-term treatment of insomnia. Some studies also found that the use of cognitive behavioral therapy (CBT) in improving the quality and quantity of sleep in primary insomnia are effective. The main methods of CBT including relaxation practice, deep breathing exercises, guided visualization, muscle exercises, stimulus control, sleep restriction and sleep hygiene ( Iliescu, Yeates and Holland, 2004; Unruh et al., 2006).

.One of the nurses' responsibilities is to make sure that patients have enough rest and sleep. Nurses should identify causes of patients' discomfort, sleep disturbance, and resolve them ( Saeedi et al.,2012 and Saeedi et al., 2014).

Breathing Exercise considered one of relaxation therapy that improves sleep by producing a significant rise in body temperature, followed by a compensatory drop a few hours later. The drop in body temperature, which persists for 2 to 4 hours after exercise, makes it easier to fall asleep and stay asleep. It also improves sleep by acting as a physical stressor to the body. The brain compensates for physical stress by increasing deep sleep (Kaur and Sharma, 2011).

Breathing exercises has an impact on breathing muscles and the muscles that support body structure. Exercise and stretching helps breathing muscles' flexibility which reduces snoring and improved lung capacity. Also, it improves sleep quality without the potential side effects of sleep medications and increases the body's production of endorphins, which create a sense of wellbeing and reduce anxiety that interfere with restful sleep (Jeon, 2004).

Progressive muscle relaxation is another type of relaxation therapy. It was developed by Dr. Edmund Jacobson more than fifty years ago. It is a method that is designed to reduce stress and anxiety. It is a systematic technique for achieving a deep state of relaxation. Dr. Jacobson discovered that a muscle could be relaxed by first tensing it for a few seconds and then releasing it. Tensing and releasing various muscle groups throughout the body produces a deep state of relaxation (Robert and Mark, 2012; Cooke, 2013).

Also, Guided Visualization is a cognitive and relaxation therapy. It is a traditional mind-body technique that is also considered a form of hypnosis. It is a relaxation technique designed to help release brain chemicals that act as body's natural brain tranquilizers, lowering blood pressure, heart rate, and anxiety levels, and improve sleep quality (Özdemør and Türkan, 2016). Therefore, the aim of this study is to evaluate the effect of these techniques (deep breathing, progressive muscle training and guided visualization) on sleep quality for patients with end stage renal disease undergoing hemodialysis.

\section{Purposeof the study:}

The purpose of the study was to evaluate the effect of relaxation techniques on the sleep quality for patients with end stage renal failure undergoing hemodialysis.

\section{Research hypothesis:}

Hemodialysis Patients who practice relaxation technique expected to have a significant improvement in sleep quality post relaxation techniques than pre relaxation techniques.

\section{Methods:}




\section{Research design:-}

The study was quasi- experimental design.

\section{Setting:-}

The study was carried out at Hemodialysis Unit at Mobark Hospital, Tanta University Hospital. The capacity of this setting is 20 beds

\section{Sampling:}

A convenient sample of 20 adult patients with end stage renal failure undergoing hemodialysis was selected. The sample size was found to be 20 patients and this calculation was based on the expected improvement of sleep quality among studied sample at $95 \%$ confidence power of the study.

Inclusion criteria:

- Adult patients (> 18 years) diagnosed with end stage renal failure.

- Having a history of hemodialysis for at least three months

- Conscious patients

- Undergone hemodialysis for 3 times per week,

- Having the acceptable ability to learn relaxation technique

\section{Exclusion criteria}

- Patients with psychological disorders as deep anxiety and depression.

- Patients with cognitive impairment and communication problems

- Patient who not willing to participate in terminally ill.

\section{Instruments: Two instrumentss were used in this study.}

- Instrument One: Interview questionnaire: This tool was developed by the researcher. It included two parts:

1. Part(1): Biosocio- demographic assessment Sheet: It includes patient's name, age, sex, marital status, educational level, occupation, date of admission, patient's lifestyle such as smoking, coffee intake, patient's medical history and duration of dialysis. This tool was developed by the researcher after reviewing the related literature.

2. Part (2): Assessment of disorders that occur during sleep. It includes uncomfortable factors during sleep in hemodialysis patients such as loud snoring, long pauses between breaths during sleep, episodes of disorientation during sleep and leg twitching or jerking during sleep.

- Instrument Two: Pittsburgh Sleep Quality Index (PSQI scale:. This tool was used to assess sleep quality. This scale was designed by Buyssue et al in 1989. It is a self-report questionnaire which measures the sleep quality during the previous month. It comprised 19 self-rated questions that yielded information related to seven components (subjective quality of sleep, delay in falling asleep, sleep adequacy, sleep duration, sleep disturbances, use of sleep medications, and daily dysfunction). The score of each component ranged from zero (no problem) to three (severe problem).

Global PSQI Score is the sum of seven components scores. The total score ranges from zero to 21 where higher scores indicate a poorer quality of sleep, score five or more shows that the person has a sleep problem, and a total score of less than five indicates a good sleep quality.

\section{Methods:}

1. Official Permission to carry out the study was obtained from the responsible authorities.

2. Informed consent was obtained from the patient after explaining the purpose of the study. 


\section{The Effect of Relaxation techniques on Quality of Sleep for Patients with End Stage Renal Failure Undergoing Hemodialysis}

3. Confidentiality of patients was ascertained.

4. The content validity of Pittsburgh Sleep Quality Index scale has been used and reported in different patient population(18).

5. Reliability testing of Pittsburgh Sleep Quality Index scale has been reported as 0.85 to 0.98 and had been tested using Chronbuk Alpha test.

6. A pilot study was carried out on 5 patients to test the feasibility and applicability of the developed tools, accordingly needed modifications were done.

7. The instruments were revised by 9 jury for content validity and modifications were done.

8. Data were collected over a 6-month period, starting from August 2013 to February 2014.

9. Assessment phase was done for all patients to collect baseline data using (tool I).

10. Pittsburgh Sleep Quality Index scale (instrument II) was used to assess the patients with sleep disturbances during the past month before the application of relaxation techniques.

11. Relaxation techniques including breathing exercise, progressive relaxation techniques and guided imagination were carried out every day for one month.

12. Each patient was individually interviewed after the assessment phase to participate in relaxation techniques and learn how to practice it.

13. Methods of education used were direct teaching methods, a combination of face-to-face methods, and demonstration and redemonstration, discussions with illustrative graphs. The content of sessions covered the following:

Session I: (General information).

The aim of this session was to provide the patients with information about aim of the study, physiology of sleep, and factors affecting sleep. The time taken for this session was 30 minutes.

Session II: Management of sleep disturbance by using breathing exercise.

This session aimed to teach the patients: Definition of breathing exercise, benefits, and technique of breathing exercise.

- Demonstration was carried out by the researcher and redemonstration was done by the patient. The time taken for this technique was 30 minutes.

- This technique was demonstrated by the patient every day for a period of one month. It includes the following:

- Regular abdominal breathing and relaxation breathing exercise.

Session III: Management of sleep disturbance using Progressive relaxation technique (PMR). This session aimed to provide information about definition, benefits of PMR, and how to perform this technique. It comprised activities as follows:

- Activities related to breathing, upper limb (shoulder, forearm and head) and chest and abdomen.

- This technique was demonstrated by the researcher and re-demonstrated by the patient for duration of 30 minutes. It was repeated every day by the patient. In this technique, each muscle group was tensed for 58 seconds and then relaxed for $15-30$ seconds.

Session IV: Management of sleep disturbance using guided visualization. This technique was taught to the patients for duration of 30 minutes. The patient was instructed to demonstrate it immediately before sleeping every day. -In this technique, the patient was taught to lie on his back, close his eyes, take deep breathing and inhale slowly 


\section{The Effect of Relaxation techniques on Quality of Sleep for Patients with End Stage Renal Failure Undergoing Hemodialysis}

and deep through nose, hold the breath for few seconds before exhaling, exhale slowly through mouth, instruct the patient to choose a place that has meaning for him and then imagine himself as in his place using all body senses.

14. Evaluation was done by using tool II again after one month of implementation of relaxation techniques to evaluate the quality of sleep after intervention and compared by the assessment phase.

\section{Statistical analysis:}

- The analysis was performed using statistical software SPSS version 16.

- For quantitative data, the range, mean and standard deviation were calculated. For qualitative data, a comparison between one group before and after intervention was done by using Chisquare test $\left(\chi^{2}\right)$. For comparison between means of one group before and after intervention, paired t-test was used. A significance was adopted at $\mathrm{P}<0.05$ for interpretation of results of tests of significance.

\section{Results:}

Table (1): Regarding age, it was observed that $55 \%$ of the studied patients were more than 50 years old, with mean age of $46.80 \pm 10.03$. More than half of samples were male $(65 \%)$ and the majority of them $(90 \%)$ were married. In relation to occupation, it was observed that $65 \%$ of patients were employed and had primary school (55\%). Regarding smoking and coffee intake, the majority of the patients $(75 \%)$ didn't smoke and $35 \%$ of patients used to drink coffee

Table (2): In relation to past medical history, more than half $(55 \%)$ of patients had past history of hypertension. Also one quarter $(25 \%)$ of patients had past history of heart disease while diabetes mellitus was encountered among $20 \%$ of studied sample.

Table (3) represents the mean score of PSQI items among studied sample one month before and one month after relaxation techniques. This table showed a significant differences in relation to dimensions of sleep quality (subjective sleep quality, sleep latency, sleep duration, habitual sleep efficacy, sleep disturbances, and day time dysfunction) before and after relaxation technique where $\mathrm{p}=0.0003,0.012$, $0.0002, \quad 0.0001,0.0004,0.001$. respectively. Also, this table showed that the mean score of total PSQI was decreased after demonstration of relaxation techniques compared with the mean score of total PSQI one month before application of relaxation techniques and a significant difference was observed where $\mathrm{P}=0.0002$.

Table (4) shows that all studied sample had poor quality of sleep one month before application of relaxation technique. On the other hand, it was observed that more than half $(65 \%)$ of studied sample reported good sleep quality after application of relaxation technique.

Table (5) represents the correlation between sociodemographic variables and total sleep quality score one month after relaxation therapy. In this table, a positive correlation was observed regarding level of education, level of occupation and total score of PSQI with $\mathrm{R}=0.814 * *$ and $0.877 * *$ respectively. Also, it was observed that educated and employed patients reported low total PSQI score with good sleep quality after application of relaxation techniques compared with non-educated and non-employed one. As regards smoking status, a significant positive correlation was observed and non-smoked patients reported low PSQI score with good sleep quality after relaxation techniques where $\mathrm{R}=0.860$. In relation to history of coffee 


\section{The Effect of Relaxation techniques on Quality of Sleep for Patients with End Stage Renal Failure Undergoing Hemodialysis}

intake, a significant positive correlation also was observed and patients used to drink coffee reported high total PSQI score with poor sleep quality compared with non-coffee intake where $\mathrm{R}=$ $0.886 * *$

Table (6) shows the mean scores of disorders that occur during sleep before and after relaxation technique. A significant improvement in the mean score of loud snoring was observed among studied sample after relaxation technique, where $\mathrm{P}=0.000$. Also, a significant improvement in mean score of long pauses between breaths and episodes of disorientation during sleep, was observed after application of relaxation technique with $\mathrm{P}=0.0002$ and 0.019 respectively. A mean score of leg twitching or jerking during sleep was also improved after techniques.

Table (7): Represents the correlation between duration of dialysis and quality of sleep after relaxation technique. It was observed that, about one third of studied sample (30\%) with duration of $<12$ month of dialysis reported good sleep quality compared with other duration of dialysis. No significant difference was observed among studied patient as regards duration of dialysis and quality of sleep after application of relaxation techniques.

Figure (1):

This figure shows that $40 \%$ of patients had dialysis for less than 12 months while only $10 \%$ of patients had more than 84 months.

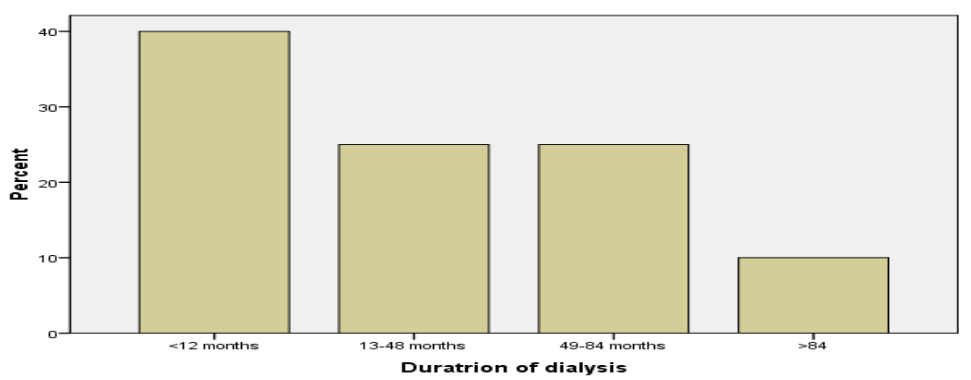

Figure (1): Distribution of the studied sample according to duration of dialysis:

Table (1): Distribution of studied groups according to Sociodemographic characteristics

\begin{tabular}{|c|c|c|c|}
\hline \multirow{2}{*}{\multicolumn{2}{|c|}{$\begin{array}{c}\text { Personal } \\
\text { Characteristics }\end{array}$}} & \multicolumn{2}{|c|}{$\begin{array}{l}\text { Studied sample } \\
\quad(\mathbf{n}=\mathbf{2 0})\end{array}$} \\
\hline & & $\mathrm{N}$ & $\%$ \\
\hline \multirow{4}{*}{$\begin{array}{c}\text { Age } \\
\text { (years) }\end{array}$} & $20-30$ & 3 & 15 \\
\hline & $31-40$ & 1 & 5 \\
\hline & $41-50$ & 5 & 25 \\
\hline & more than 50 & 11 & 55 \\
\hline \multicolumn{2}{|c|}{ Mean \pm SD } & \multicolumn{2}{|c|}{$46.80 \pm 10.035$} \\
\hline \multirow[t]{2}{*}{ Sex } & Male & 13 & 65 \\
\hline & Female & 7 & 35 \\
\hline \multirow[t]{2}{*}{ Marital status } & Married & 18 & 90 \\
\hline & Single & 2 & 10 \\
\hline \multirow[t]{3}{*}{ Education } & Primary school & 11 & 55 \\
\hline & Technical high school & 2 & 10 \\
\hline & Illiterate & 7 & 35 \\
\hline \multirow[t]{2}{*}{ Occupation } & Employed & 13 & 65 \\
\hline & Unemployed & 7 & 35 \\
\hline \multirow[t]{2}{*}{ Smoking } & Nonsmoker & 15 & 75 \\
\hline & Smoker & 5 & 25 \\
\hline \multirow[t]{2}{*}{ Coffee intake } & No & 13 & 65 \\
\hline & Yes & 7 & 35 \\
\hline
\end{tabular}


The Effect of Relaxation techniques on Quality of Sleep for Patients with End Stage Renal Failure Undergoing Hemodialysis

Table (2) Distribution of the studied sample according to medical conditions:

\begin{tabular}{|c|c|c|c|c|c|c|}
\hline \multirow{2}{*}{$\begin{array}{c}\text { Studied sample } \\
(\mathbf{n = 2 0})\end{array}$} & \multicolumn{6}{|c|}{ Medical history } \\
\cline { 2 - 7 } & \multicolumn{2}{|c|}{ DM } & \multicolumn{2}{c|}{ Hypertension } & \multicolumn{2}{c|}{ Heart disease } \\
\cline { 2 - 7 } & No & Yes & No & Yes & No & Yes \\
\hline N & 16 & 4 & 9 & 11 & 15 & 5 \\
\hline$\%$ & 80 & 20 & 45 & 55 & 75 & 25 \\
\hline
\end{tabular}

Table (3): Mean score of PSQI items among the studied sample month before and month after relaxation techniques:

\begin{tabular}{|c|c|c|c|}
\hline \multirow[b]{2}{*}{ PSQI items } & \multicolumn{2}{|c|}{ Mean \pm SD } & \multirow[b]{2}{*}{$\begin{array}{l}\mathbf{t} \\
\mathbf{P}\end{array}$} \\
\hline & $\begin{array}{l}\text { Month } \\
\text { Before }\end{array}$ & $\begin{array}{c}\text { Month } \\
\text { After } \\
\end{array}$ & \\
\hline Subjective sleep quality & $1.60 \pm 0.883$ & $0.65 \pm 0.489$ & $\begin{array}{c}4.498 \\
0.0003 *\end{array}$ \\
\hline Sleep Latency & $1.70 \pm 0.733$ & $0.95 \pm 0.686$ & $\begin{array}{c}2.775 \\
0.012 *\end{array}$ \\
\hline Sleep duration & $1.75 \pm 1.070$ & $0.40 \pm 0.598$ & $\begin{array}{c}4.239 \\
0.0002 *\end{array}$ \\
\hline Habitual sleep efficiency & $2.25 \pm 0.786$ & $0.70 \pm 0.733$ & $\begin{array}{c}6.307 \\
0.0001 *\end{array}$ \\
\hline Step disturbances & $2.00 \pm 0.649$ & $1.10 \pm 0.553$ & $\begin{array}{c}4.723 \\
0.0004 * \\
\end{array}$ \\
\hline Use of sleeping medication & $0.05 \pm 0.224$ & $0.002 \pm 0.0003$ & $\begin{array}{l}1.000 \\
0.330\end{array}$ \\
\hline Daytime dysfunction & $1.60 \pm 0.940$ & $0.65 \pm 0.587$ & $\begin{array}{c}4.046 \\
0.001 *\end{array}$ \\
\hline Total PSQI & $10.95 \pm 2.282$ & $4.45 \pm 1.820$ & $\begin{array}{c}\mathbf{8 . 8 9 3} \\
0.0002 *\end{array}$ \\
\hline
\end{tabular}

* $\mathbf{P}$ is significant at the 0.05 level.

Table (4): the effect of relaxation techniques on sleep quality among studied sample

\begin{tabular}{|c|c|c|c|c|c|}
\hline \multirow[t]{2}{*}{$\begin{array}{l}\text { Quality of sleep } \\
\text { (Total PSQI) }\end{array}$} & \multicolumn{2}{|c|}{$\begin{array}{l}\text { Month } \\
\text { before } \\
(\mathbf{n}=\mathbf{2 0})\end{array}$} & \multicolumn{2}{|c|}{$\begin{array}{c}\text { Month after } \\
\quad(\mathbf{n}=\mathbf{2 0})\end{array}$} & \multirow[t]{2}{*}{$\begin{array}{l}\chi^{2} \\
\mathbf{P}\end{array}$} \\
\hline & $\mathbf{N}$ & $\%$ & $\mathbf{N}$ & $\%$ & \\
\hline $\begin{array}{c}<5 \\
\text { "Good sleep quality" }\end{array}$ & 0 & 0 & 13 & 65 & \multirow{2}{*}{$\begin{array}{r}60.381 \\
0.108\end{array}$} \\
\hline $\begin{array}{c}5-21 \\
\text { "Poor sleep quality" }\end{array}$ & 20 & 100 & 7 & 35 & \\
\hline
\end{tabular}

$P$ is significant at the 0.05 level.

Table 5: correlation between sociodemographic variables and total sleep quality (total PSQI) month after relaxation techniques.

\begin{tabular}{|c|c|c|}
\hline \multirow{2}{*}{ Variables } & \multicolumn{2}{|c|}{$\begin{array}{c}\text { Total PSQI } \\
\text { month after }\end{array}$} \\
\cline { 2 - 3 } & $\mathbf{R}$ & $\mathbf{P}$ \\
\hline Age. & $\mathbf{0 . 1 1 5}$ & $\mathbf{0 . 6 3 0}$ \\
\hline Sex & $\mathbf{0 . 1 8 6}$ & $\mathbf{0 . 4 3 2}$ \\
\hline Marital status & $\mathbf{0 . 1 7 8}$ & $\mathbf{0 . 4 5 1}$ \\
\hline Education & $\mathbf{0 . 8 1 4} * *$ & $\mathbf{0 . 0 0 0 1} *$ \\
\hline Occupation & $\mathbf{0 . 8 7 7} * *$ & $\mathbf{0 . 0 0 0 2} *$ \\
\hline Smoking & $\mathbf{0 . 8 6 0} * *$ & $\mathbf{0 . 0 0 0 1} *$ \\
\hline Coffee intake & $\mathbf{0 . 8 7 7} *$ & $\mathbf{0 . 0 0 0 3} *$ \\
\hline
\end{tabular}

**. Correlation is significant at the 0.01 level.

*. Correlation is significant at the 0.05 level.

Table (6): mean score of disorders that occurs during sleep before and after relaxation techniques. 
The Effect of Relaxation techniques on Quality of Sleep for Patients with End Stage Renal Failure Undergoing Hemodialysis

\begin{tabular}{|c|c|c|c|}
\hline \multirow[b]{2}{*}{ Factors } & \multicolumn{2}{|c|}{ Mean \pm SD } & \multirow[b]{2}{*}{$\begin{array}{l}\mathbf{t} \\
\mathbf{P}\end{array}$} \\
\hline & $\begin{array}{l}\text { Month } \\
\text { Before }\end{array}$ & $\begin{array}{c}\text { Month } \\
\text { after }\end{array}$ & \\
\hline Loud snoring & $2.10 \pm 1.021$ & $0.40 \pm 0.681$ & $\begin{array}{c}7.373 \\
0.0001\end{array}$ \\
\hline Long pauses between breaths while asleep & $1.05 \pm 0.826$ & $0.15 \pm 0.366$ & $\begin{array}{c}5.604 \\
0.0002\end{array}$ \\
\hline Legs twitching or jerking while asleep & $0.75 \pm 0.910$ & $0.30 \pm 0.571$ & $\begin{array}{l}1.831 \\
0.083\end{array}$ \\
\hline Episodes of disorientation during sleep & $0.70 \pm 1.081$ & $0.10 \pm 0.308$ & $\begin{array}{l}2.565 \\
0.019\end{array}$ \\
\hline
\end{tabular}

Table (7): correlation between duration of dialysis and quality of sleep after relaxation techniques.

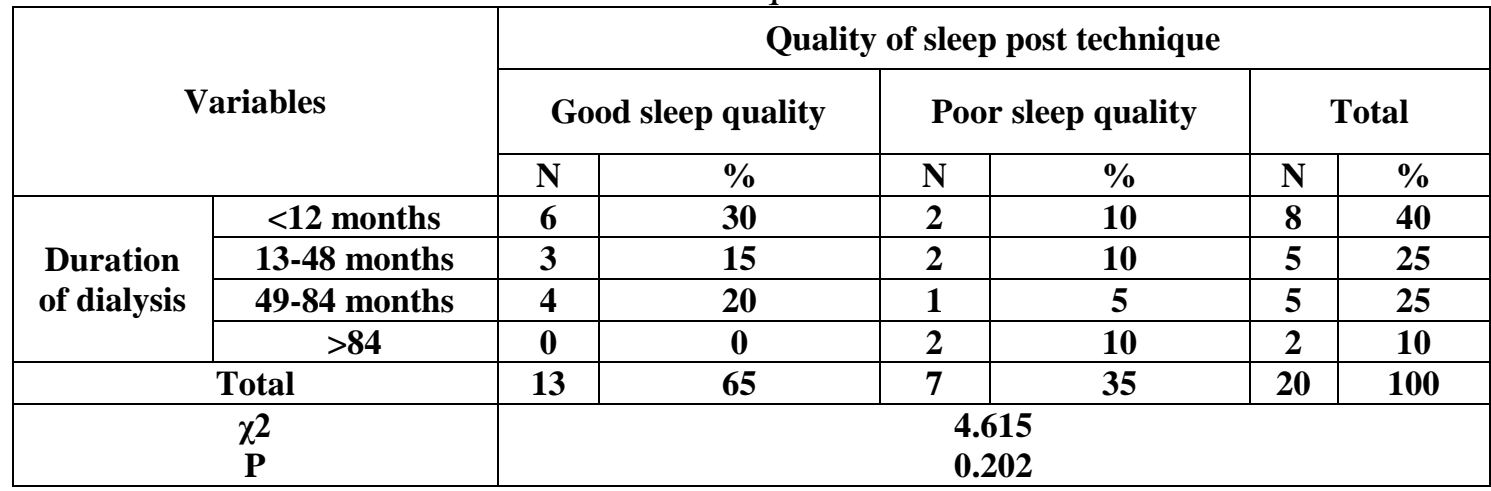

$P$ is significant at the 0.05 level.

\section{Discussion}

Good sleep quality is an important factor not only for living healthy but also for leading a physically and mentally productive life. Many patients on regular hemodialysis have sleep disorders, which not only affect their quality of life but also their immune function; thus, causing inflammatory disorders and cardiovascular diseases(1). According to previous studies, around $50-80 \%$ of dialysis patients have problems associated with sleep disorders, including a difficulty in falling asleep, waking up early, daytime sleepiness, leg jerking and trembling (Chen, Lim and $\mathrm{Wu}, 2006$ )

Sleep is important for promoting hospitalized patients recovery and improves the life quality of everyone (Richards, 1998).

Relaxation techniques are designed simply to teach patients to relax, and thus improve their ability to sleep. There are several relaxation methods; none has been shown to be more efficacious than the others. The aim of relaxation techniques is to achieve physical and mental relaxation. They are meant to reduce physical tension and interrupt the flow of thoughts that is preventing sleep (Agency for Healthcare Research and Quality (AHRQ), 2005; Montgomery \& Dennis, 2004).

Regarding biosociAL characteristics, the finding of the present study reveals that majority of the sample was more than 50 years old. This contributed that aging process may have experienced a decrease in sleep quality. This finding was in line with Iliescu et al., (2003) who mentioned that sleep difficulties are closely correlated with older age in patients with end stage renal failure.

The present finding shows that majority of the patients were male and married. This result was contradicting with Al-Jahdali et al., (2010) who reported that females were more strongly affected with insomnia than males. In relation to occupation, it was observed the majority of the patients 


\section{The Effect of Relaxation techniques on Quality of Sleep for Patients with End Stage Renal Failure Undergoing Hemodialysis}

were employed. This may be attributed to occupational stress that has attributed their sleep disturbance and overtime work causing disturbed sleep. This agrees with Frighetto et al., (2004) who reported a strong relation between sleep quality and occupational stress.

Also, it was found that nearly one fourth of the studied samples were smokers. The same results were reported by Unruh et al., (2006) who emphasized that cigarette smoking was associated with lower sleep quality during the first year of dialysis therapy. This could be due to the stimulating effects of nicotine that could cause smokers to experience nicotine withdrawal each night, which may contribute to disturbances in sleep. In addition, Holley et al., (1991) emphasized that hemodialysis patients with sleep disorders were more likely to smoke cigarettes. Also, the present study showed that nearly one third of the patients drink coffee. In this regard, Benz et al., (1999) confirmed that poor sleep quality of hemodialysis patients is associated with caffeine intake. On the other hand, Sabbatini et al., (2002) showed that caffeine intake was an insignificant factor for the development of insomnia in ESRD.

Regarding past medical history, it was found that majority of the study sample had history of diabetes mellitus and heart diseases and about half of them had history of hypertension. This may be attributed to renal failure is a result of direct vascular abnormalities that accompany diabetes. Furthermore, diabetes mellitus is the main cause of end-stage renal disease (ESRD). Poor sleep quality in people with diabetes was associated with worse control of their blood glucose levels. This result was supported by Taylor et al., (2007) and Shu-Yu (2011) whose results revealed that the prevalence of heart disease, hypertension and diabetes mellitus were higher in those with insomnia.

Also, the findings of the present study shows that the mean scores of subjective sleep quality sleep latency, sleep duration, sleep disturbances, sleep efficiency and daytime dysfunction were significantly improved after relaxation techniques except the use of sleep medications. None of patients used sleeping pills and they were scored as " 0 " in the area of "using sleep medications. This improvement may be contributed that relaxation exercises causing reduction of anxiety and depression, increased social interaction, stabilization in sympathetic activity and increased energy conservation. This finding was in accordance with Saeedi et al., (2014) who stated that the mean scores of each of the dimensions of sleep quality were significantly lower in the intervention group.

Regarding the effect of relaxation techniques on the quality of sleep measured by Pittsburgh Sleep Quality Index (PSQI), the current study revealed that all the studied patients reported a poor quality of sleep one month before intervention. On the other hand, majority of the studied patients had a significantly great improvement in global sleep quality one month after the application of relaxation techniques. This study was in agreement with lashkari et al., (2013), Mollaoğlu (2009) and pathak et al., (2013). They concluded that cognitive behavioral treatments include progressive muscle relaxation, guided imagery and deep breathing improved total score of sleep quality and its dimensions in hemodialysis patients.

According to correlation between the demographic variables and total sleep quality after relaxation technique, the present study showed a positive correlation between the level of education and the quality of sleep after the application of relaxation techniques. 


\section{The Effect of Relaxation techniques on Quality of Sleep for Patients with End Stage Renal Failure Undergoing Hemodialysis}

A total PSQI score was decreased with good sleep quality among highly educated and employed hemodialysis patients. This may be attributed to educated and employed patients responding effectively to the researcher's instructions and they believed that these interventions are considered as a part of their management. In addition, these patients differ from other non-educated patients in their level of understanding and cooperation. This result was supported by Rotem et al., (2008), Saeedi et al (2014) , Neethu et al., (2012). They concluded that both low educational level and cultural factors correlate significantly with poor sleep quality.

Also, it was observed that a total score of PSQI was decreased among nonsmokers and non coffee intake hemodialysis patients. Smoking and coffin intake are stimulants and have negative effects on hemodialysis patients. Smoker patient and patient who drink coffe does not respond effectively to relaxation techniques due to the effects of these stimulants. This result was in accordance with Saeedi et al., (2012) who illustrated that smoking and coffee intake had negative impacts of quality of sleep.

The present study also reveals that no significant correlation was reported among the studied sample in relation to age, sex and marital status and quality of sleep after the application of relaxation techniques. This may be due to the small sample size as well as the total population of end stage renal failure with hemodialysis. This findings was in contrast with Sabet (2012), Iliescu et a.,1 (2003) and Mollaoğlu (2004) who reported that when age increased, sleep quality decreased and advanced age affects patients experiencing sleep problems. Similarly, community- based studies have shown that the sleep quality could be deteriorated in elderly patients due to the increased frequency of physical diseases and multiple drug use. Also, Saeedi et al (2012) was not on the line with the present study, they found that female patients were negatively correlated with quality of sleep and reported a low PSQI score compared with male patients.

Regarding uncomfortable factors during sleep in hemodialysis before and after relaxation techniques, the findings of the present study showed that the mean score of loud snoring and long pauses between breathing were improved among the studied sample after the application of relaxation techniques. In addition, the mean score of legs twitching or jerking with sleeping was improved after relaxation intervention. A build-up of waste in the blood can cause hemodialysis patient to feel irritable and uncomfortable and make sleeping difficult.

This result was in line with Sabet et al., (2012) and Dehdari et al., (2009). They reported that end stage renal failure with hemodialysis commonly experience sleep problems such as loud snoring, long pauses between breathing and twitching movement patient. Also, they found that these problems disappeared after relaxation therapy.

Also, the present study shows that episodes of disorientation during sleep disappeared and a significant improvement was observed a month after the application of relaxation techniques. This result was in line with Sadeghi (2010) who found that hemodialysis patients had more problems in their functionality during daytime, which can affect their day time alertness, activity level, the incidence of accidents and overall wellbeing.

In relation to the duration of dialysis, the findings of the current study reported that no significant correlation between duration of dialysis, total score of PSQI and quality of sleep a month 


\section{The Effect of Relaxation techniques on Quality of Sleep for Patients with End Stage Renal Failure Undergoing Hemodialysis}

after the relaxation techniques. This result was in contrast with the results of Sabet et al., (2012), Sabbatini (2002) and Han (2002) who showed a correlation between the duration of hemodialysis treatment of patients and sleep quality and stressed that the risk of insomnia was found to be higher in patients with a longer history of dialysis (more than one year).

Finally, according to this study, it can be concluded that all the hemodialysis patients with end stage renal failure have a poor quality of sleep. Relaxation techniques are effective in improving sleep and sleep quality. Thus, all nurses in every medical setting should learn the relaxation techniques and consider this as a routine nursing intervention.

\section{Conclusion:}

According to the findings of this study, it can be concluded that patients on hemodialysis had a poor sleep quality in terms of total PSQI scores. Also, professional nurses have an important role in addressing and evaluating the poor sleep quality in hemodialysis patients. Periodic clinical assessment and early identification of sleep problems and complaints should become a routine for dialysis staff. They should not concentrate only on medical treatment, but they should also help these patients to practise behavioral and cognitive therapies and acquire a healthy lifestyle. Relaxation techniques such as breathing exercise, guided imagery and muscle training, have a positive effect on the sleep quality of hemodialysis patients.

The PSQI survey is a simple tool offering complete information on sleep quality. Therefore, it should be encouraged in all hemodialysis patients since it presents the first step to detect poor sleepers in order to begin a more accurate procedure for early diagnosis and treatment.

\section{Recommendations:}

Based on the findings and conclusion of this study, the following are recommended:

1. Periodic clinical assessment of sleep complaints should become routine for dialysis staff. Also, non-pharmacologic methods such as behavioral techniques, relaxation and cognitive therapies should be used for the treatment of sleep problems in hemodialysis patients.

2. Further research for nurses should focus on identifying new methods and treatment techniques aiming at improving sleep quality.

3. Also, in-services training program should be directed towards improving both knowledge and practice of professional nurses; especially, those who are caring for patients undergoing hemodialysis.

4. Periodic assessment of hemodialysis patients by using The Pittsburgh Sleep Quality Index (PSQI) should be carried out by professional nurses to assess sleep quality.

5. Further research for patients. Patient's attitudes and their perception towards relaxation techniques should be modified by continuing health education and further researches in this field.

\section{Reference}

Agency for Healthcare Research and Quality (AHRQ). Manifestations and management of chronic insomnia in adults. June 2005 [Accessed on: July 25, 2005] (Evidence Report/Technology Assessment; Volume 125).

Ahmed A, Mohd F, Allam E,Habill A, Metwally N, Ibrahiem M, 


\section{The Effect of Relaxation techniques on Quality of Sleep for Patients with End Stage Renal Failure Undergoing Hemodialysis}

Radwan M,El-Gaafary , Afifi A , Gadallah M. Development of practice guidelines for hemodialysis in Egypt, Indian $\mathrm{J}$ Nephrol, 2010; 20(4): 193-202.

Al-Jahdali H, Khogeer H, Qadhi W, Baharoon S, Tamim H, Hejaili F, Ghamdi $\mathrm{S}$ and Al-Sayyari A. Insomnia in chronic renal patients on dialysis in Saudi Arabia, Journal of Circadian Rhythms, 2010; 8(7): 1-7.

Benz R, Pressman R, Hovick T and Peterson D. A preliminary study of the effects of anemia with recombinant human erythropoietin therapy on sleep, sleep disorders, and daytime sleepiness in hemodialysis patients , Am J Kidney Dis, 1999 ; 34: 1089-1095.

Brandenberger G, Viola A , Ehrhart J , Charloux A , Geny B, Piquard F\& Simon C. Age-related changes in cardiac autonomic control during sleep, Sleep Res J, 2003; 12(3): 173-180.

Buysse D, Reynolds C, and Monk T. Quantification of subjective sleep quality in healthy elderly men and women using the Pittsburgh Sleep Quality Index (PSQI), Sleep J. 1991;14:331-8.

Chen W, Lim P and Wu W. Sleep behavior disorders in a large cohort of Chinese (Taiwanese) patients maintained by long-term hemodialysis, Am Kidney Dis J, 20061; 48: 277-284.

Cooke H. Progressive Muscle Relaxation, CAM-Cancer J, 2013; 1(1):1-6.

Dehdari T, Heidarnia A, Ramezankhani A, Ghofranipour S. Effects of progressive muscular relaxation training on quality of life in anxious patients after coronary artery bypass graft surgery, Indian J Med Res, 2009;129(1): 603608 .
Frighetto L, Marra C, Bandali S, Wilbu $K$ and Naumann T. An assessment of quality of sleep and the use of drugs with sedating properties in hospitalized adult patients,

Holley L, Nespor S, Rault R. Characterizing sleep disorders in chronic hemodialysis patients, ASAIO Trans, 1991; 37: (1): 456-M457.

Iliescu E, Coo H, McMurray M, Meers C and Quinn M. Quality of sleep and health-related quality of life in haemodialysis patients, Nephrol Dial Transplant J, 2003; 18(1): 126-132

Merlino G, Piani A, Dolso P, Adorati M, Cancelli I, Valente M. Sleep disorders in patients with end stage renal disease undergoing dialysis therapy,Nephrol Dial Transplant J,2006; 21(1): 184190.

Mollaoğ M. Sleep in Patients with ESRD Undergoing Hemodialysis, Progress in Hemodialysis- From Emergent Biotechnology to Clinical Practice, Angelo Carpi, (2011); ISBN: 978-953-307-3774 ,

Mollaoğlu M. Depression and Health Related Quality of Life in Hemodialysis Patient, Dialysis Transplant J, 2004; 33(1) : 544555.

Montgomery P \& Dennis J. A systematic review of nonpharmacological therapies for sleep problems in later life, Sleep Med Rev J, 2004; 8: 47-62.

Neethu F, D'silva F. Effectiveness of Progressive Muscle Relaxation Therapy on Quality of Sleep among Patients Admitted in Medical Ward of a Selected Hospital in Mangalore, Inter $\mathbf{J}$ Nursing Education,2012;4(2):4650 . 


\section{The Effect of Relaxation techniques on Quality of Sleep for Patients with End Stage Renal Failure Undergoing Hemodialysis}

Özdemør F,Türkan P. The Effects of Training and Progressive Relaxation Exercises On Anxiety Level after Hysterectomy, the New Journal of Medicine, 2009; 26(1): 102-107

Pathak P, Mahal R, Kohli A, Nimbran V. Progressive Muscle Relaxation: An adjuvant therapy for reducing pain and fatigue among hospitalized cancer patients receiving radiotherapy, Inter J Advan Nurs Studies, (2013);2 (2): 58-65.

Richards K. Effect of back massage and relaxation intervention on sleep in critically ill patients, American Journal of Critical Care, 1998; 7(1): 288-299.

Robert L, Mark R. Pressman M. Sleep Disorders Associated with Chronic Kidney Diseasea, (2012). ISBN: $\quad$ 978-953-51-0171-0. Available from:http://www.intechopen.co $\underline{m} /$

Sabbatini M , Minale B, Crispo A, Pisani A, Ragosta, A, Esposito $\mathrm{R}$ and Cesaro $\mathrm{A}$. Insomnia in maintenance hemodialysis patients, Nephrol Dial Transplant, 2002; 17(1) : 852-856.

Sabet R, Mehdi M, and Azar S. Quality of sleep in dialysis patients, Iranian Journal of Nursing and Midwifery Research, 2012; 17(4):270-74

Sadeghi H, Azizzadeh F Haghdust A, Mohammad A. Effect of implementing continuous care model on sleep quality of hemodialysis patients, Iranian Journal of Critical Care Nursing Spring, 2010; 3,(1): 13-18.

Saeedi M, Ashktorab T, Saatchi K, Zayeri $\mathrm{F}$ and Amir S. The Effect of Progressive Muscle Relaxation on Sleep Quality of Patients Undergoing Hemodialysis, Iranian Journal of
Critical Care Nursing, 2012; 5(1): $23-28$.

Saeedi M, Shamsikhani S, Farahani P, Haghverdi F. Sleep Hygiene Training Program for Patients on Hemodialysis, Iranian Journal of Kidney Diseases, 2014;8(1).

Santo R, Bartiromo M, Cesare C, and Di Iorio B. Sleeping Disorders in Early Chronic Kidney Disease, Semin Nephrol J, 2006;26(1):6467.

Shu-Yu C and Te-Cheng Y. Sleep Quality and Associated Factors in Hemodialysis Patients, Acta Nephrologica J, 2011; 25(3): 97104.

Taylor J, Mallory J, Lichstein K, Durrence H, Riedel B and Bush A. Comorbidity of chronic insomnia with medical problems, Sleep J, 2007; 30(1) : 213-18.

Totem T, Arnon Z, Haimov I. The effect of music relaxation versus progressive muscular relaxation on insomnia in older people and their relationship to personality traits, J music Ther, 2008; 45(3):360-80.

Unruh M, Buysse D, Dew M, Evans I, Fink N, Powe N, Meyer K. Sleep Quality and Its Correlates in the First Year of Dialysis, Clin J Am Soc Nephrol, 2006;1(1): 802810. 